Laurent Z. X. Li

\title{
Atmospheric GCM response to an idealized anomaly of the Mediterranean sea surface temperature
}

Received: 17 October 2005 / Accepted: 4 April 2006

(C) Springer-Verlag 2006

evaporation rate much larger than the rainfall rate and river discharge, which implies oceanic convection and deep water formation.

Paleo-climatic archives reveal that the Mediterranean has experienced important variations in the past. The Mediterranean Sea was isolated from the global ocean about 6 million years ago. A sea-level drop of more than $1,500 \mathrm{~m}$ took place at that time (Hsu et al. 1973; Krijgsman et al. 1999) due to the strong evaporation, which in turn led to a much cooler sea surface temperature (SST). For the Last Glacial Maximum, 21,000 years ago, the temperature around the Mediterranean basin was decreased by more than $10 \mathrm{~K}$, and the eastwest temperature gradient was $4 \mathrm{~K}$ larger than that existing today (Hayes et al. 2005). The Eastern Mediterranean Transient (Lascaratos et al. 1999; MalanotteRizzoli et al. 1999), a drastic shift of the Mediterranean convection at the end of the 1980s and the beginning of 1990s, also illustrates the large variability that can occur in the present-day Mediterranean Sea.

Rixen et al. (2005) studied the evolution of the Mediterranean thermal structure during the last 50 years and concluded that the Mediterranean thermal content $(0-150 \mathrm{~m})$ is strongly correlated to the North Atlantic Oscillation (NAO) in the atmosphere, which induces important air-sea heat flux anomalies over the region. Cooler air temperatures are actually observed around the Mediterranean basin when the NAO is in its positive phase (Hurrell 1995; Thompson and Wallace 2001). The positive trend of the NAO during the last decades may limit the warming of the Mediterranean Sea due to the increased anthropogenic green-house effect. It may even explain the cooling $(-0.3 \mathrm{~K})$ of the Mediterranean Sea upper layer from 1960s until the end of the 1980s (Rixen et al. 2005). The latter is confirmed in HadISST, another observation-based dataset (Rayner et al. 2003). Figure 1 gives the leading principal component of the SST from HadISST, showing clearly the Mediterranean surface cooling from 1960 to 1980 , with a maximum in the Eastern Mediterranean. The hydrological cycle of the Mediterranean Sea is also highly correlated to the NAO

Laboratoire de Météorologie Dynamique,

IPSL/CNRS, casier 99, Université Pierre et Marie Curie, 4, place Jussieu, 75252 Paris Cedex 05, France

E-mail: li@1md.jussieu.fr

Fax: + 33-1-44276272 
EOF 01 (45\%) DJF 1950/1999
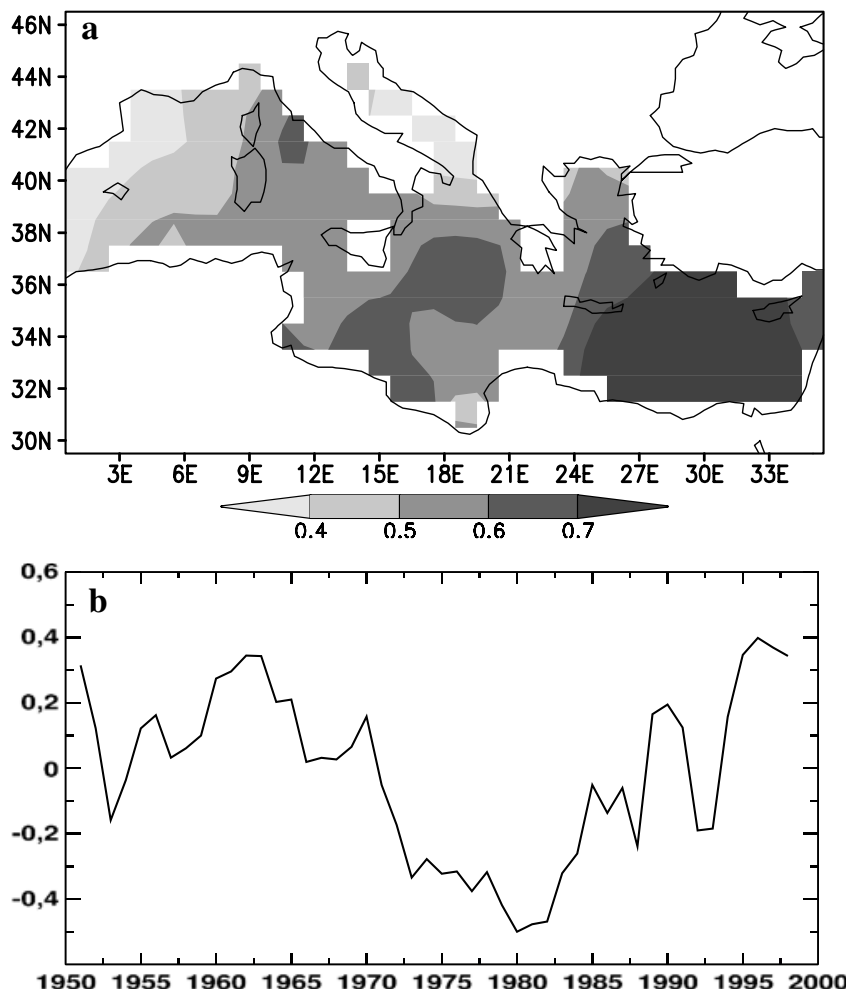

Fig. 1 Leading spatial structure (a, arbitrary units) and temporal coefficient (b, arbitrary units) of a principal component analysis of the winter (January, February and December of the precedent calendar year) Mediterranean sea surface temperature (K) during the second half of the twentieth century. This structure explains $45 \%$ of the total variance. $\mathrm{b}$ is plotted with a three-point running mean

(Mariotti et al. 2002; Struglia et al. 2004). The main motivation of this study is to investigate the nearby and remote climate influences of a Mediterranean cooling which may be the consequence of a prolonged positive NAO period.

In the context of anthropogenic global warming, the Mediterranean Sea is a minimum warming centre, compared to the surrounding lands (IPCC 2001; Chapter 9). It is believed that the increasing sea-land thermal contrast, together with the increasing trend of the NAO, is a factor causing the decrease of mean precipitation as reported in Alpert et al. (2002), Milan et al. (2005) and Norrant and Douguedroit (2006), and the decrease of mean cloudiness as reported in Maugeri et al. (2001). The second motivation of this study is to investigate the effect of an increased thermal contrast between the Mediterranean Sea and its surrounding lands for anthropogenic global warming.

This work is also a first step towards understanding the interactive role of the Mediterranean Sea in climate changes. Only the atmospheric response to SST anomalies is studied without considering feedbacks to the sea. Rowell (2003) also used a fixed Mediterranean SST anomaly in an atmospheric GCM to study the active role of the Mediterranean Sea. He found that with a warmer Mediterranean the Sahelian summer rainfall is increased through an increase of moisture transport in the eastern part of the Sahara. He remarked that the rainfall increase is also amplified by a more intense moisture flux from the tropical Atlantic ocean and a more intense local water re-cycling.

The present paper is organized in the following manner. Section 2 presents the model used and the experimental design. The climatological circulation of the control atmosphere is presented in Sect. 3. Results are given in Sect. 4 and some conclusions in Sect. 5.

\section{Design of experiments}

The model used is version 3.2 of LMDZ, the atmospheric general circulation model developed at LMD (Laboratoire de Météorologie Dynamique). It is derived from the standard LMD model described in Sadourny and Laval (1984). The dynamical core is resolved through the grid-point method. A brief description of the physical parameterization and climate simulation performance can be found in $\mathrm{Li}$ (1999). It is a state-ofthe-art climate model, already used in $\mathrm{Li}$ and Conil (2003a) to produce a 1,000-year ocean-atmosphere coupled simulation. It was also used in Zhou and $\mathrm{Li}$ (2002) to study the Asian summer monsoon, and in $\mathrm{Li}$ and Conil (2003b) and Conil and Li (2005) for NAOrelated questions. The spatial resolution is $72 \times 45$ points $\left(5^{\circ} \times 4^{\circ}\right)$, regularly distributed in the longitudelatitude coordinates. There are 19 layers in the vertical.

The model is run in the perpetual January mode, with fixed solar incoming radiation and prescribed soil moisture at their climatological values. The use of a perpetual mode was needed to accomplish the large amount of simulations described below. It also helps to clarify the interpretation of results since the background flow remains always fixed.

To simplify the experimental design, we introduce an idealized situation by imposing a homogeneous cooling of $2 \mathrm{~K}$ for the Mediterranean sea surface (13 model points for the current resolution). Such cooling is much larger than the effect $(-0.3 \mathrm{~K})$ of increasing NAO during the last decades (Rixen et al. 2005; see also Fig. 1), but it corresponds well to the increased surface thermal contrast between the Mediterranean Sea and the surrounding lands predicted by many climate models for the end of the twenty-first century (IPCC 2001; Chapter 9). The experimental design used here does not imply any Mediterranean cooling in the context of an anthropogenic global warming. It is just a surrogate to investigate the effect of the Mediterranean minimum warming centre in comparison to a larger warming on the surrounding lands. Furthermore, the simplicity of our experimental design will provide a more efficient simulation protocol for intercomparison of models. 
Two sets of experiments are conducted. The first one is the traditional equilibrium control experiment of 9,000 days (EXP0e in Table 1). Such a long duration guarantees the statistic significance of results (see Sect. 4.3).

The second set is a transient experiment (in the sense of transition to equilibrium) as described in $\mathrm{Li}$ and Conil (2003b) or Ferreira and Frankignoul (2005). The approach to equilibrium of an ensemble transient simulation is very useful to reveal the temporal evolution of the response. Different mechanisms can thus be separated, identified and quantified. The experiment consists of conducting an ensemble of meteorological sequences with same boundary conditions but different initial states. When the ensemble size is sufficiently large, the mean meteorological sequence (ensemble average of all the sequences) will be stable and representative of the January conditions. For the current study, the length of the meteorological sequences is 30 days and the ensemble size is 3,000 .

To avoid initial adjustment of the model, all initial states are the "re-starting points" of a model simulation, at 30-day interval. In practice, we performed another long-duration (90,000 days) run and saved model states every 30 days as initial states. This long run is actually the control simulation of our transient experiment (EXP0t in Table 1). The 3,000 initial states can be considered as independent since duration 30 days is beyond the meteorological autocorrelation time scale (see also Fig. 6c, $d$ in Sect. 4.3). The large ensemble size is not only to increase the statistical significance, but also to ensure the entire coverage of all possible weather situations, producing a reliable and representative climatology.

The sensitivity simulations will be referred to as EXP2e and EXP2t which are the same as EXP0e and EXP0t (same model code, same computing configuration and same initial states), but with a $-2 \mathrm{~K}$ anomaly in the Mediterranean Sea (boundary conditions). Table 1 summarizes all the simulations conducted in this study. Differences between EXP2(e,t) and EXP0(e,t) reveal thus the influences of the imposed boundary forcing - a Mediterranean SST cool anomaly. The equilibrium run allows assessment of the final response at equilibrium. The transient run allows a study of the temporal evolution of the response and reveals multi modes or

Table 1 Main characteristics of the numerical simulations: simulation type (equilibrium or transient), sea surface temperature as boundary conditions ("observed" means 1979-2002 averaged climatology), simulation length (days) and ensemble size

\begin{tabular}{lllll}
\hline Simulation & Type & SST & $\begin{array}{l}\text { Length } \\
\text { (days) }\end{array}$ & $\begin{array}{l}\text { Ensemble } \\
\text { size }\end{array}$ \\
\hline EXP0e & Equilibrium & Observed & 9,000 & 1 \\
EXP2e & Equilibrium & $-2 \mathrm{~K}$ & 9,000 & 1 \\
EXP0t & Transient & Observed & 30 & 3,000 \\
EXP2t & Transient & $-2 \mathrm{~K}$ & 30 & 3,000 \\
\hline
\end{tabular}

regimes of response since they often have different time scales (Kushnir et al. 2002; Li and Conil 2003b).

\section{Climatological circulation}

Before discussing the impacts of a Mediterranean SST cool anomaly, it is useful to present some climatological characteristics of the control simulation. They serve as an element of model validation and they will also be invoked in explaining the model responses.

Figure 2 displays the mean zonal wind at $300 \mathrm{hPa}$ (top) and sea-level pressure (bottom), for both the control simulation (EXP0e) and the ERA-15 dataset (European centre for medium-range weather forecast, re-analysis, 15 years from 1979 to 1993). We examine firstly the sea-level pressure. The permanent atmospheric centres of action for the winter season are two Lows (Aleutian and Icelandic) and two Highs (subtropical North Pacific and North Atlantic). The two subtropical Highs have their maximum centres near the coast of North America and the coast of West Europe and North Africa. The Siberian High is a seasonal centre of action. Generally speaking, the model is successful in capturing the main behaviours of the atmospheric mean state. The Aleutian Low seems however slightly shifted to the west in the model.

For the zonal wind at $300 \mathrm{hPa}$, the double spiral structure (composed of Asia-North Pacific jet-stream and North America-North Atlantic jet-stream) is the most remarkable one in Fig. 2. The Asian jet-stream begins in the North Atlantic, near the African coast. It crosses the Middle East and the whole Asian continent before joining the North Pacific jet-stream. A strong deceleration takes place in the middle of the North $\mathrm{Pa}$ cific. The North Atlantic jet-stream has a more meridional component and is tilted towards Northern Europe. Again the model captures well the main features of the mean atmospheric circulation, although the North Atlantic and the North Pacific jet-streams are about $10 \mathrm{~m} / \mathrm{s}$ stronger than their observational counterparts.

\section{Atmospheric responses}

\subsection{Equilibrium response}

We will now discuss the atmospheric response to the Mediterranean SST anomaly. Figure 3 displays the geopotential height response (EXP2e-EXP0e) in the equilibrium experiment for, from bottom to top, 1,000, 850,500 and $300 \mathrm{hPa}$, respectively. It is clear that the response is mainly found in the Northern Hemisphere and there is almost no signal in the Southern Hemisphere. In the Mediterranean region, slightly downstream of the forcing centre (eastern Mediterranean basin, Black Sea and Caspian Sea), there is a baroclinic structure with high pressure near the surface and low pressure in the upper layers. The transition height is 
Fig. 2 January sea-level pressure $(\mathrm{hPa}$, at the bottom) and $300-\mathrm{hPa}$ zonal wind $(\mathrm{m} / \mathrm{s}$, on the top), simulated by the model (left panels) and revealed by the ERA-15 dataset (right panels) for the period $1979 / 1993$ $\exp 0: U 300(\mathrm{~m} / \mathrm{s})$

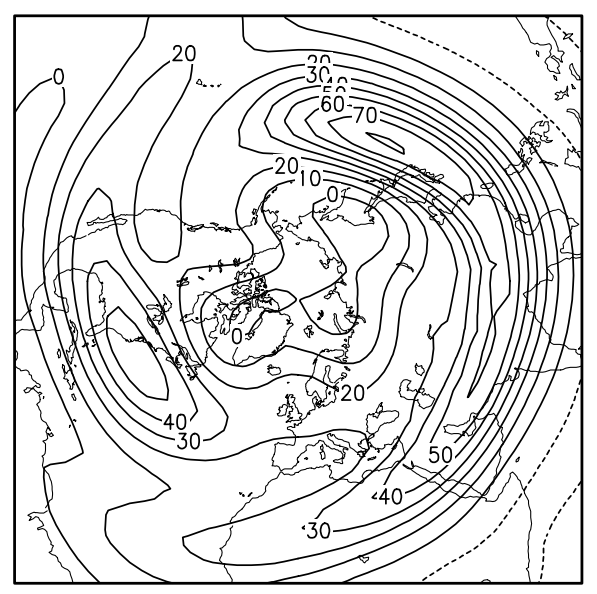

exp0: SLP $(\mathrm{hPa})$

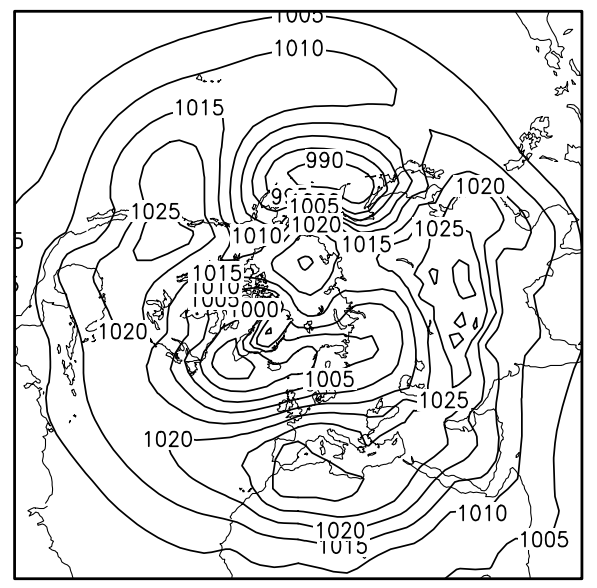

ERA15: U300 (m/s)

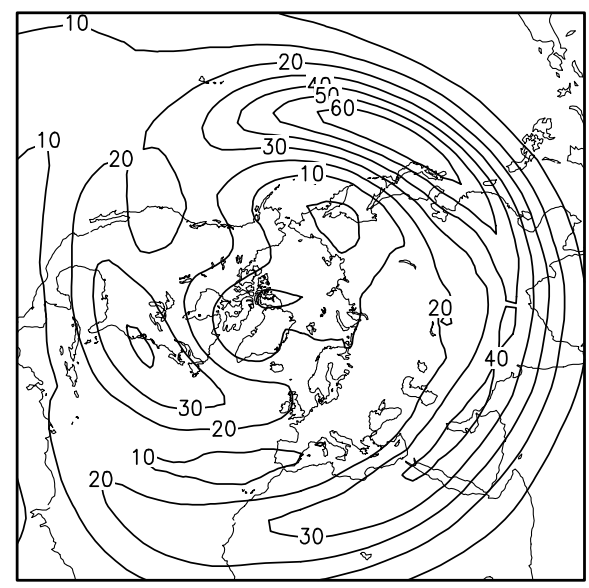

ERA: SLP ( $\mathrm{hPa})$

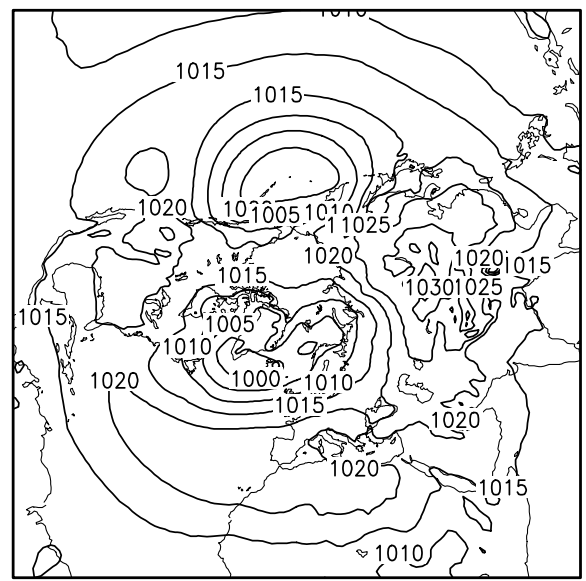

slightly higher than the $850-\mathrm{hPa}$ level. This structure extends eastwards following the Asian jet-stream until the exit of the Eurasian continent. Such a baroclinic response of the atmosphere is a direct response to the Mediterranean Sea cooling and it is consistent with the vorticity theory about a surface thermal forcing, as reviewed by Frankignoul (1985) and Kushnir et al. (2002). The intensity of this baroclinic structure is about $5 \mathrm{~m}$ at $1,000 \mathrm{hPa},-10 \mathrm{~m}$ at $500 \mathrm{hPa}$ and $-15 \mathrm{~m}$ at $300 \mathrm{hPa}$. This baroclinic response is much weaker than the theoretically calculated maximum baroclinic response (about $20 \mathrm{~m} / \mathrm{K}$ for $500 \mathrm{hPa}$ ) (Kushnir et al. 2002) for the North Atlantic or North Pacific basin-scale SST anomalies. The weakness of the atmospheric response here may be related to the much smaller size of the Mediterranean Sea, and also to the descending motion over the Mediterranean which keeps the adiabatic heating in the very low layers of the atmosphere. This was already pointed out in $\mathrm{Li}$ and Conil (2003b) for the subtropical centre of the North Atlantic SST tripole structure. It is also noted that an opposite-sign baroclinic structure, weak but statistically significant (see Sect. 4.3; Fig. 7), is formed in South Asia, just south of the Eurasian baroclinic anomaly.
We now examine the Euro-Atlantic region and plot the changes of rainfall $(\mathrm{mm} /$ day $)$ in Fig. 4 . We also add the variations of sea level pressure (hPa) and the associated $10-\mathrm{m}$ wind $(\mathrm{m} / \mathrm{s})$. For the whole Mediterranean Sea, a decrease of precipitation is observed and the amplitude reaches $-0.25 \mathrm{~mm} /$ day. It is consistent with the decreasing trend of the observed precipitation associated with the cooling SST during the last decades (Alpert et al. 2002). It is also consistent with a decreasing rainfall in this region projected by many climate models under global warming due to increasing greenhouse gases.

Decreases of rainfall are also simulated in a large sector of the North Atlantic, following the European coast. This is consistent with the high-pressure anomaly present in the Euro-Atlantic sector, which induces cold and dry air mass advection from the North. However, the precipitation increases near the North-East Coast of the Mediterranean Sea, from the Adriatic Sea to the Black Sea, related to low-level wind convergence. The increase in precipitation south of Greenland and north of Scandinavia is consistent with the low-level wind convergence and an increase of warm and humid air mass transport from the South and from the ocean. 

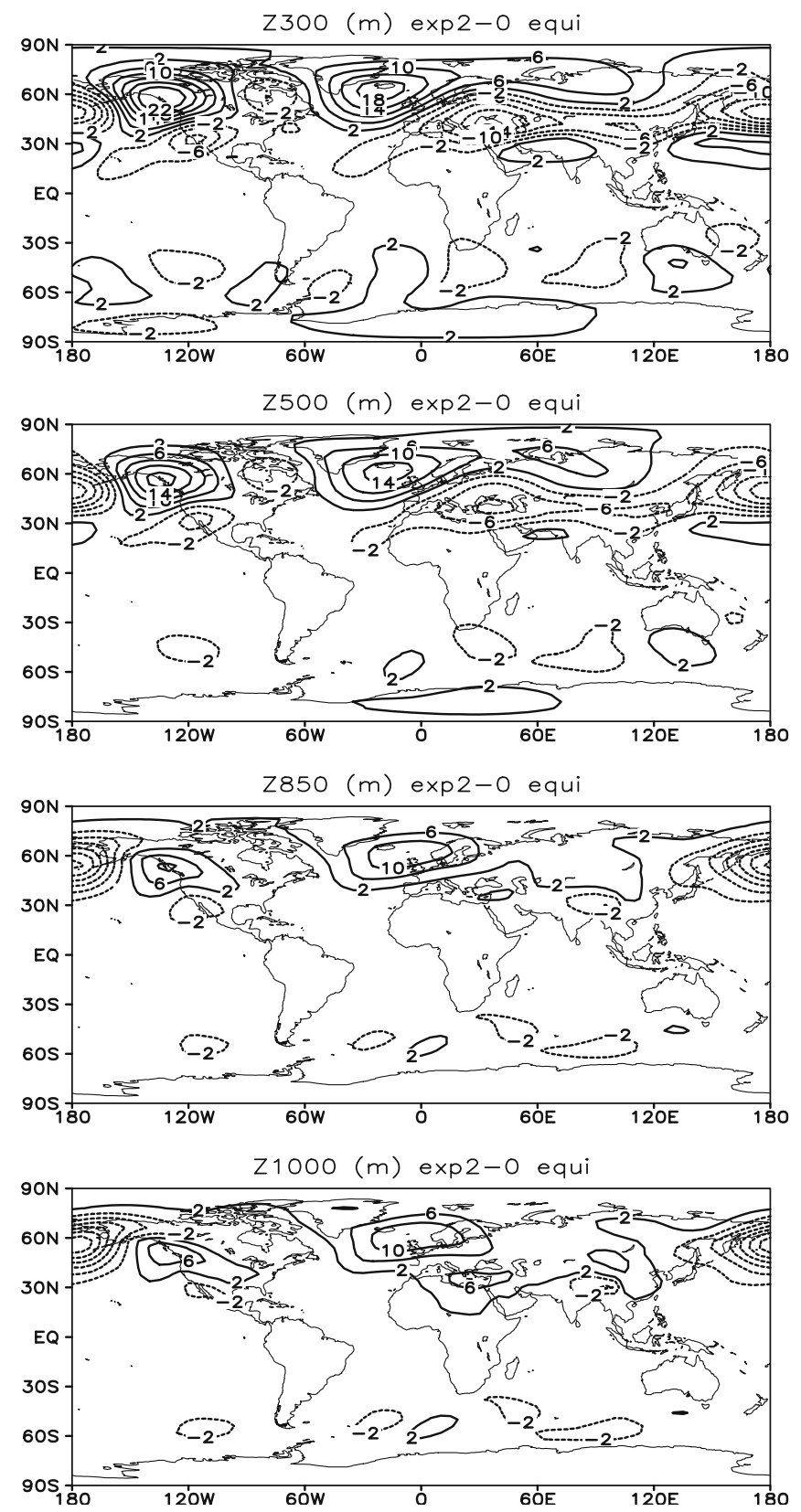

Fig. 3 Geopotential height anomalies $(\mathrm{m})$ simulated in the equilibrium experiment for, from top to bottom, 300, 500, 850 and $1,000 \mathrm{hPa}$, respectively. Contour interval is $4 \mathrm{~m}$. Negative anomalies are dashed

Far from the Mediterranean, the source of the initial anomaly, two other regions can be identified with important responses (Fig. 3). The first region is over the North Atlantic where a quasi-barotropic high pressure is observed with a small tilt to the West from the surface to the tropopause. A centre of $10 \mathrm{~m}$ at $1,000 \mathrm{hPa}$ is over the triangle formed by the British Isles, Iceland and Scandinavia. This anomaly reaches $15 \mathrm{~m}$ at $300 \mathrm{hPa}$ with a centre of action around Iceland. This North Atlantic response has also a zonally elongated structure to the East following roughly the Arctic coast. This
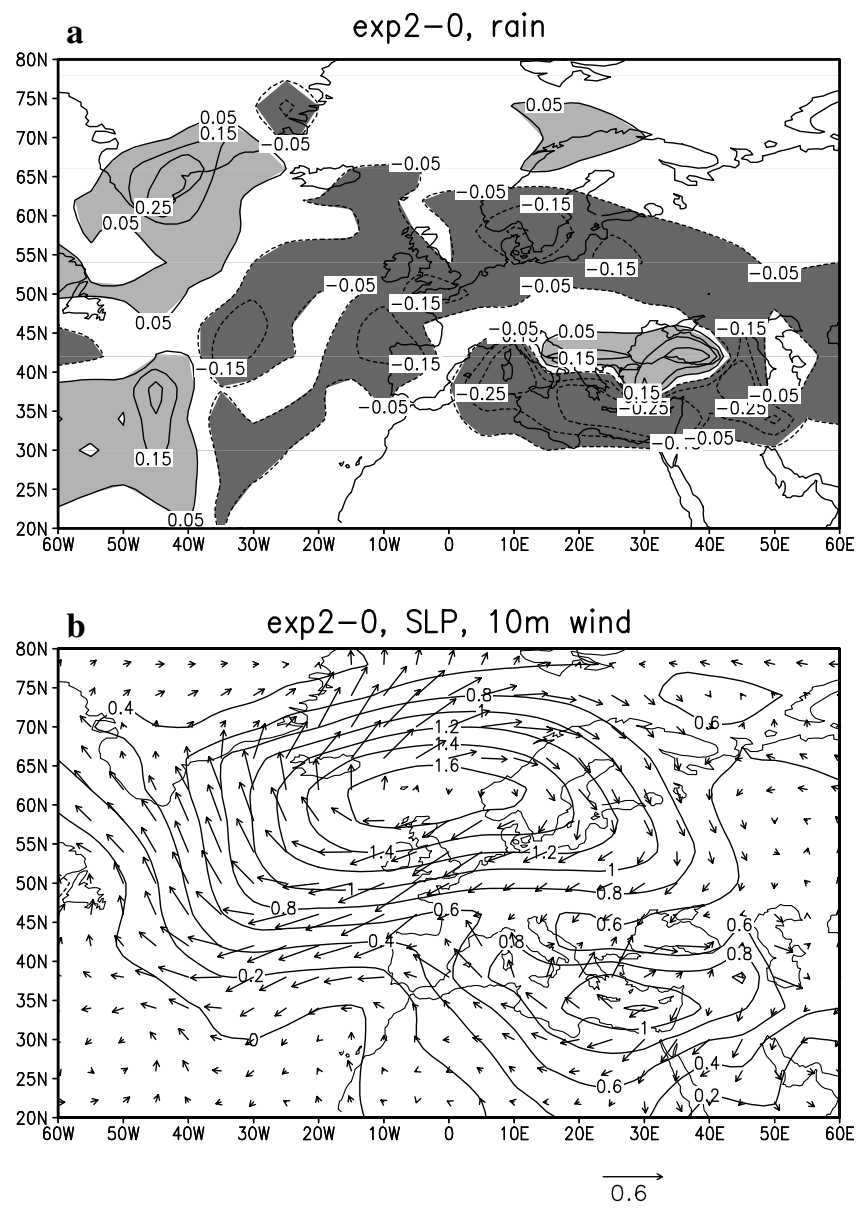

Fig. 4 Anomalies of precipitations (a, mm/day, heavy shading for decrease and light shading for increase), sea-level pressure (b, $\mathrm{hPa}$, contour with interval of $0.2 \mathrm{hPa}$ ) and $10-\mathrm{m}$ wind $(\mathbf{b}, \mathrm{m} / \mathrm{s}$, the small vector at the bottom represents $0.6 \mathrm{~m} / \mathrm{s}$ ). Only the geographical sector of the North Atlantic, Europe and the Mediterranean is displayed

situation corresponds to a decrease of the NAO index. The second region of large response is over the North Pacific where barotropic structures are again observed with a slight tilt to the West from the surface to the tropopause. The Aleutian Low is deepened through the whole troposphere with an anomaly of $-20 \mathrm{~m}$. A wavetrain is formed following the Pacific Coast.

The existence of large-scale zonally propagated teleconnection structures was already pointed out by Branstator (2002). He demonstrated that the Asian jetstream starting over North Africa played a role of waveguide by trapping disturbances inside the jet-stream and propagating them from West to East. Watanabe (2004) also found that there is a downstream extension of the NAO during late winter through a wavetrain which is interpreted as quasi-stationary Rossby waves trapped on the Asian jet waveguide and excited by the anomalous upper-level convergence over the Mediterranean Sea. He concluded that the Mediterranean convergence associated to the NAO may have some predictability for the medium-range weather forecast in East Asian countries. 

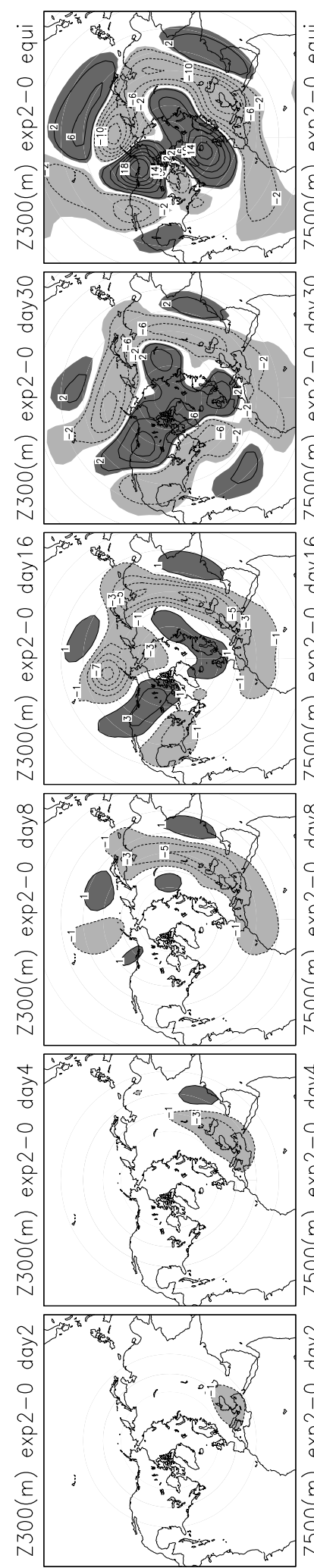
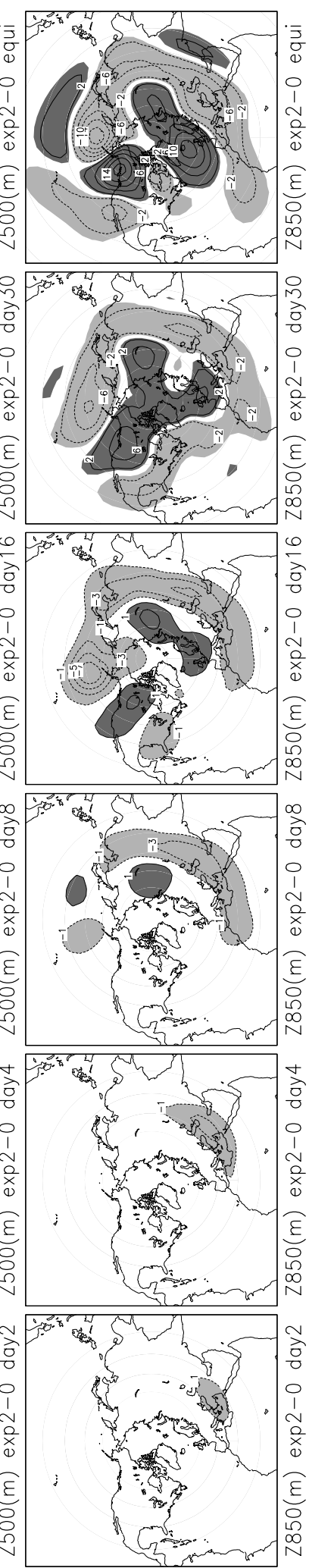
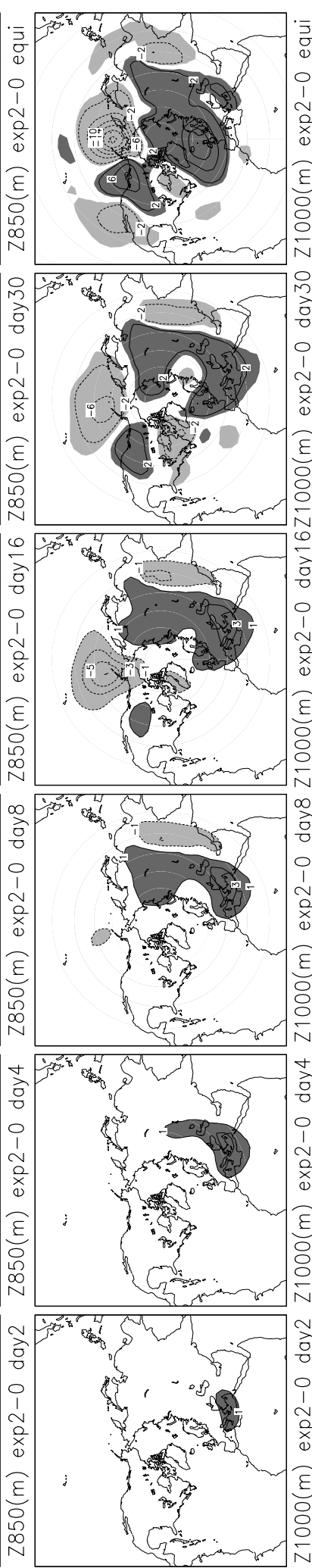
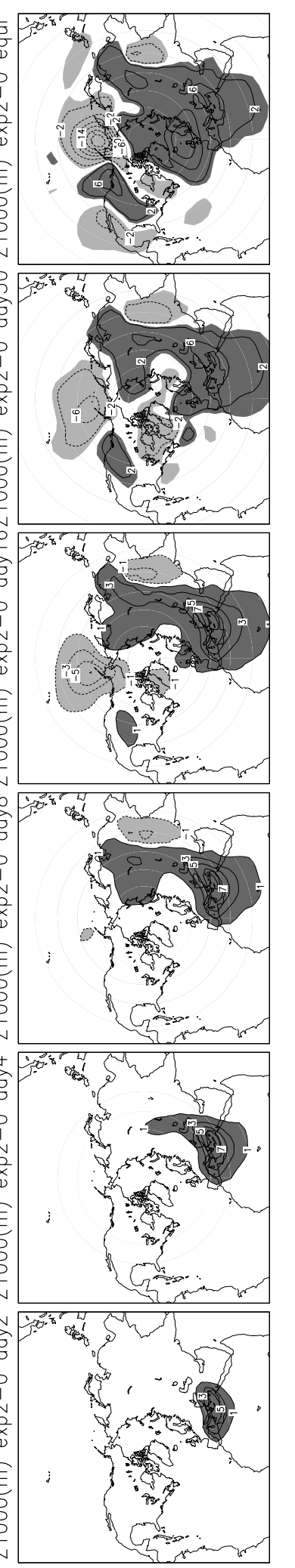

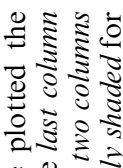

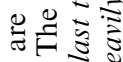

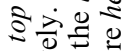

ㅇ.

₹

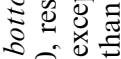

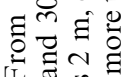

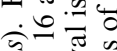

इ $\infty$ 氙

8त.

过密要

후원

苟哇方令

氖. 氜

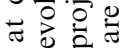

플 르

จ을

뭉

응

눙

表范

도용

용

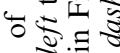

응

을 음

声焉

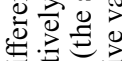

च远

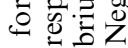

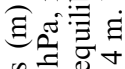

.

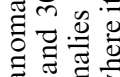

응

등응

¿ 8

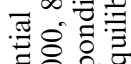

풍요

릉

o $0: 0$

ن.

을. 
$\mathrm{Yu}$ and Zhou (2004) reported that the cooling trend observed during the recent half century for the subtropical Eurasian continents in Spring is highly correlated to the winter NAO. They found also that the signal had an apparent slow eastward propagation, from North Africa to Central Asia, in a quasi-barotropic structure for the whole troposphere. But this seasonal slow evolution does not necessarily indicate any propagative time scale, it may only reveal the natural seasonal cycle of the NAO. Yu et al. (2004) concluded furthermore that a local positive cloud feedback was largely responsible for the signal amplification downstream of the Tibetan Plateau.

\subsection{Transient response}

Let us now study the temporal evolution of the response by examining the transient experiment (EXP2t-EXP0t). Figure 5 plots the geopotential height anomalies for different levels and at different times. The results of the equilibrium experiment are also plotted in the last column. When the cooler Mediterranean SST is added, the baroclinic response appears quickly (several metres for the geopotential height on the second day) and is mainly located downstream - from the Eastern Mediterranean basin to the Caspian Sea. This structure develops further with time and propagates across the Eurasian continent. The signal seems to reach its final geographic extension
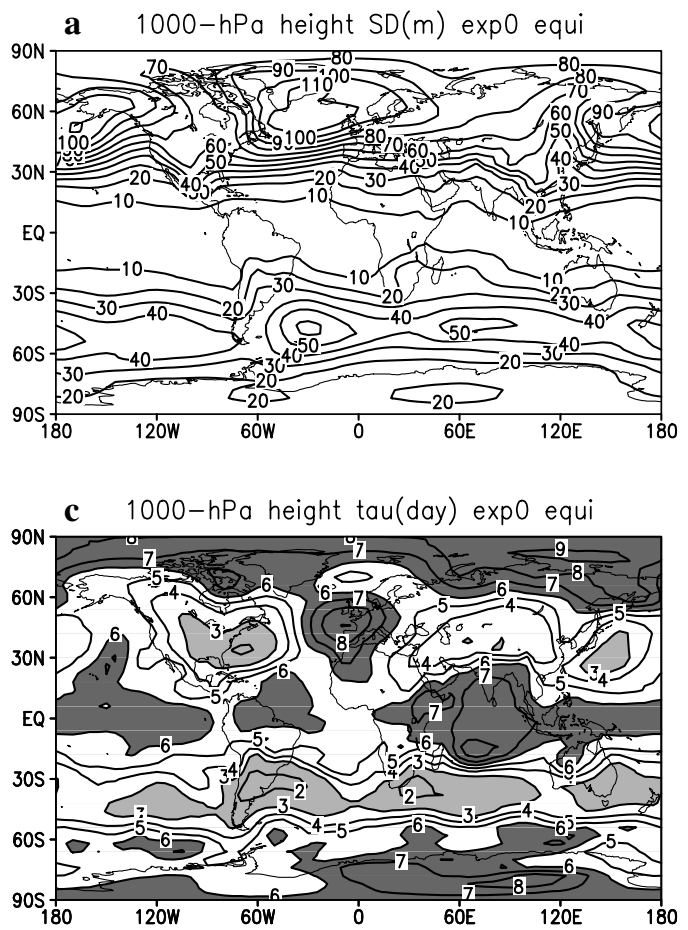

Fig. 6 Standard deviation $\sigma_{1}(\mathrm{~m} ; \mathbf{a}, \mathbf{b})$ and autocorrelation time scale $\tau$ (days; c, d) deduced from the day-to-day values of 1,000hPa geopotential height for January. a, c are from 9,000 days of the simulation EXP0e. b, d are from the NCEP (National Centers for on day 8 , but continues to grow while the global mean state changes. Even at day 30, the end of the transient experiment, the intensity of this baroclinic structure is still weaker than that in the equilibrium experiment.

We have already mentioned that the two remarkable remote responses in the atmosphere are in the North Pacific and North Atlantic. Now from the time evolution of the response, we can see that, on day 8, anomalies appear in the North Pacific, mainly in the upper layers, but with a downward propagation to make the whole atmospheric column into a barotropic situation. From day 8 to day 16 , the negative anomaly in the North Pacific continues to grow and induces new anomalies with a wavetrain to the South-East, into the American continent.

Two other structures should be noted on day 8: one is the appearance of the baroclinic anomaly (positive for high layers and negative for low layers) in South Asia, probably related to precipitation anomalies (and associated latent heat release) produced in the tropics; another is the barotropic structure (positive anomaly) located in Siberia. The South Asia baroclinic structure does not evolve very much after day 8 , but the Siberian high seems to intensify and propagates to the West to the British Isles. From days 16 to 30, the signal from the North Pacific and North America also reaches to Europe, and the positive anomaly over North-West Europe is amplified by perturbations from the North Atlantic. Even at the end of the transient experiment (day 30), the
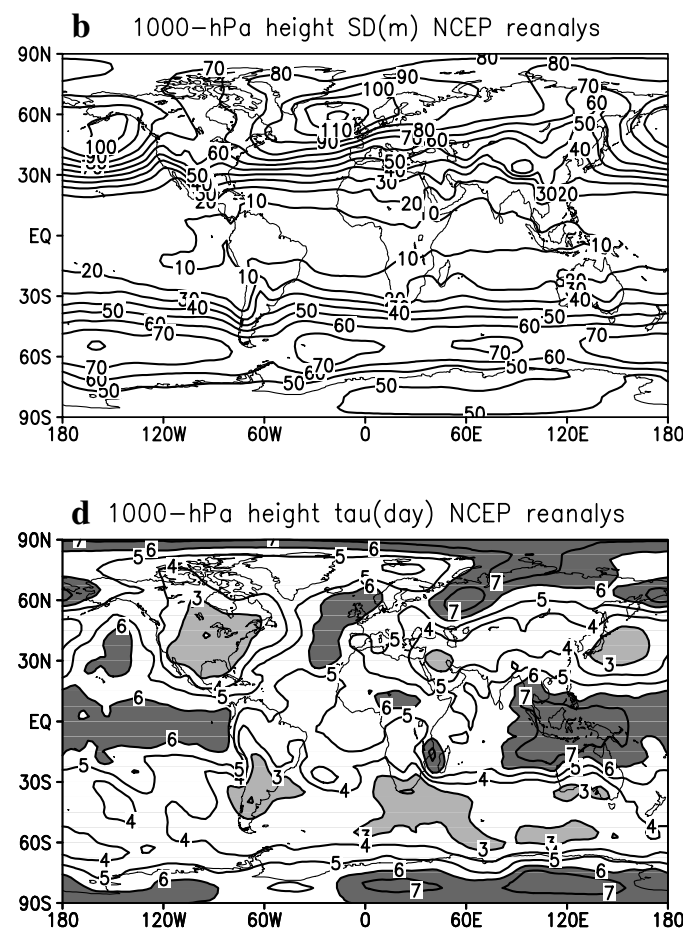

Environmental Prediction) re-analysis for 40 months of January from 1964 to 2003. For c, d regions with values less than 3 days are lightly shaded, and those with values more than 6 days are heavily shaded 
North-West Europe positive anomaly is still in a preliminary stage compared to its final equilibrium structure with a huge extension following the Arctic Coast. The time scale of this structure is thus beyond the period of 30 days and the contribution from the North Pacific and North America seems dominant for its formation and maintenance. Such a connection relating the North Atlantic to the North Pacific through wave activities across North America has already been pointed out by Honda et al. (2001) and it is believed to be the responsible mechanism for the seesaw between the Aleutian and Icelandic Lows (Honda et al. 2005).

\subsection{On the statistical significance}

Although the response signals of the present study are weak, they are physically coherent and they are also believed statistically significant with the very large ensemble size. To make a formal demonstration, firstly we present the day-to-day standard deviation (SD, noted as $\sigma_{1}$ ) in Fig. 6a, as obtained through the 9,000-day simulation of EXP0e. For the sake of conciseness, only the SD of 1,000-hPa geopotential height is given, but the same conclusions apply to other levels. The observed counterpart, as deduced from 40 months of January (1964-2003) in the NCEP reanalysis (Kalnay et al. 1996), is plotted in Fig. 6b. The model has a quite good performance in simulating the SD which varies from about $10 \mathrm{~m}$ in the tropics to more than $100 \mathrm{~m}$ in mid and high latitudes. In the Northern Hemisphere, two main centres of action are located over the North Atlantic and North Pacific - regions of maximum storminess.

The SD calculated in such a manner, however, cannot be directly used in statistical significance testing, since the synoptic sequences are auto-correlated, which induces the dependence of statistical samples. The decorrelation length $\tau$ is estimated as in $\mathrm{Li}$ (1999) by $\tau=\sum_{i=-20}^{i=+20} r_{i}$

where $r_{i}$ is the autocorrelation coefficient with a lag of $i$ days. It is clear that $\tau$ indicates the number of days required to gain a new degree of freedom. The lower panel of Fig. 6c, d presents the geographic distribution of this autocorrelation time scale $\tau$, depicted in both model and observation. The results are consistent with our general knowledge that the atmospheric persistence is about a few days.

With the above consideration, we are now able to make the estimation of the standard deviation $\sigma_{N}$ for the Gaussian distribution that the $N$-member (day) average represents

$\sigma_{N}=\sigma_{1} / \sqrt{N / \tau}$

The quantity $t=1.65 \sigma_{N} / \sqrt{2}$ is the threshold above which a difference is statistically significant with a confidence level at $95 \%$. Here, $\sqrt{2}$ indicates that we have two ensembles of size $N$, the number 1.65 is the value for the cumulative normal distribution function to reach $95 \%$. Figure $7 \mathrm{a}$, showing the geographic distribution of $t$ for $N=9,000$, can be directly used to deduce the statistical significance of the equilibrium experiment.

For the transient experiment, we have 3,000 independent realizations. It is thus correct to put $\tau=1$ when $\sigma_{3000}$ is calculated. The corresponding quantity $t$ is given in Fig. $7 \mathrm{~b}$, suitable for checking the statistical significance of the transient experiment. Due to the "perpetual January" characteristic of our simulations, the ensemble-averaged meteorological sequence of 30 days provides another possibility to estimate the SD $\sigma$ :

$\sigma^{2}=\frac{1}{30} \sum_{d=1}^{30}\left(x_{d}-\bar{x}\right)^{2}$
$95 \%$ size 9000

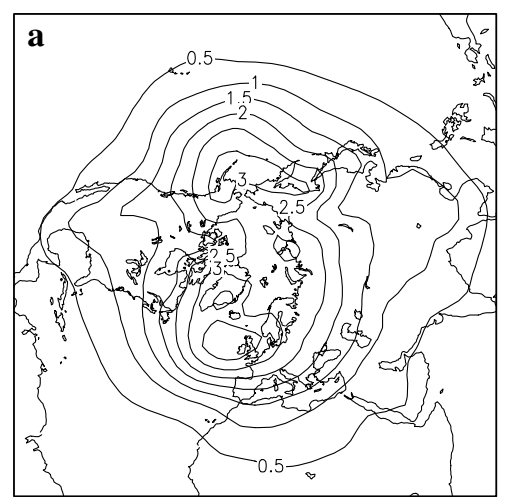

95\% size 3000 indep. $\mathrm{m} 1$

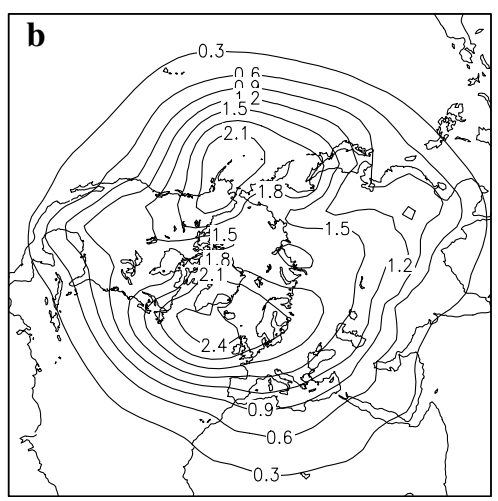

95\% size 3000 indep. $\mathrm{m} 2$

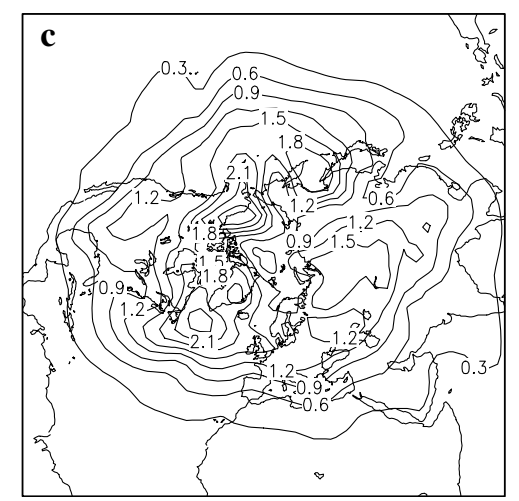

Fig. 7 Threshold (m) of 95\% statistical confidence test for 1,000$\mathrm{hPa}$ geopotential height (a difference above the threshold is statistically significant with a confidence level at 95\%). a (contour interval $0.5 \mathrm{~m}$ ) is for the equilibrium runs with 9,000 consecutive days of simulation. b, c (contour interval $0.3 \mathrm{~m}$ ), deduced by two different approaches, are for the transient runs with 3,000 independent realizations 
where $x_{d}$ is the ensemble average of 3,000 independent elements, $\bar{x}$ the time average of $x_{d}$. The corresponding quantity $t=1.65 \sigma / \sqrt{2}$, plotted in Fig. $7 \mathrm{c}$, is also suitable for checking the statistical significance of the transient experiment. The two approaches give very similar results, showing the robustness of our calculations.

We can see that the results presented in Figs. 3 and 5, at least the main centres and structures, passed the $95 \%$ confidence level.

\section{Conclusions}

In the present paper, we hypothesized and demonstrated for the first time that the Mediterranean Sea could initiate atmospheric teleconnections and thus influence the weather and the climate for remote regions. The reason that the global atmospheric circulation can be sensitive to a Mediterranean forcing is related to the particular geographic location of the Mediterranean Sea in the north flank of the winter Northern Hemisphere jetstream and to its closeness to the main centres of action of the NAO.

In the present work, we used an idealized Mediterranean homogeneous cooling of $2 \mathrm{~K}$ and imposed such a forcing in the LMDZ atmospheric general circulation model. By analysing both equilibrium and transient runs, we can draw the following conclusions.

1. A baroclinic structure is created downstream of the anomalies, across the entire Eurasian continent, roughly following the subtropical jet-stream. There are high (low) pressure anomalies in the lower (upper) atmosphere. Unlike the results for the North Atlantic presented in Ferreira and Frankignoul (2005), Li and Conil (2003b) and Peng and Whitaker (1999) showing the appearance of an equivalent barotropic structure through the feedback of anomalous transient eddy fluxes, we did not observe such an evolution in the Mediterranean region. Possibly the equivalent barotropic structure was not strong enough to mask the direct baroclinic structure. This is certainly related to the weakness of the transient eddy activity over the region, as remarked in $\mathrm{Li}$ and Conil (2003b) concerning the subtropical zone of the North Atlantic. We can reasonably imagine that this conclusion will be enhanced in summer, since the eddy activity is weaker than in winter. Over South Asia, an opposite-sign baroclinic structure is obtained and it is believed to be related to a tropical rainfall anomaly.

2. For the geographical sector including the North Atlantic, Europe and the Mediterranean, the sea-level pressure variation is finally dominated by two positive anomalies. The first one is over the Eastern basin of the Mediterranean Sea and is related to the direct thermal response of the atmosphere. The second one is over the North-East Atlantic through indirect effects from the North Pacific and North America.
Note that this positive anomaly over the North-East Atlantic was still in its preliminary stage at the end (day 30) of the transient experiment. It is thus not excluded that other mechanisms, such as wavetrains from the Tropical Atlantic, may play their role at longer time scales. Corresponding to the anomalies of the sea level pressure, precipitation decreases over the Mediterranean area and Europe, but it increases near the north coast of the Mediterranean (Adriatic Sea to Black Sea) related to the wind convergence in the lower atmosphere.

3. The most remarkable remote influence of a Mediterranean cold anomaly is over the North Pacific with a deeper Aleutian Low and a corresponding stronger high pressure over the North American continent. The structure begins to form several days after the introduction of forcing and grows to its final stationary stage in several tens of days. The growing process is mainly initiated in the upper layers of the troposphere and a clear downward propagation is visible. This result is consistent with the works of Branstator (2002) and Watanabe (2004) invoking the waveguide role of the Asian jet-stream.

4. Several days after the beginning of the forcing, we observe an equivalent barotropic high-pressure anomaly in Siberia, to the north of the Asian jetstream. This Siberian positive anomaly propagates further to the West and a barotropic high-pressure anomaly is thus initiated in the Euro-Atlantic sector. At the same time, when the Aleutian Low in the North Pacific deepens, positive anomalies grow for the Icelandic Low (Honda et al. 2001, 2005). Finally, a huge positive (high-pressure) anomaly is formed in the North Atlantic, with a strong zonal elongation following the Arctic coast. Such a situation corresponds to a weakening of the NAO with a decreased meridional pressure gradient, which counteracts the Mediterranean cooling. A weak negative feedback between the NAO and the Mediterranean Sea can thus be speculated.

5. The North Pacific and North Atlantic anomalies take a longer time to appear and have a clear origin in the upper troposphere, which is in favour of the theoretical considerations based on atmospheric transient circulation and interaction between the mean flow and transient eddies (Peng and Whitaker 1999; Kushnir et al. 2002). Our results are in agreement with those of Honda et al. $(2001,2005)$ revealing the seesaw structure between the Aleutian Low in the North Pacific and the Icelandic Low in the North Atlantic.

The present study is only a preliminary step towards understanding the interactive role of the Mediterranean Sea in the complex climate system. In the future, it will be interesting to study feedbacks from the atmosphere into the Mediterranean Sea, and take into account the full coupling between the Mediterranean Sea and the atmospheric circulation. 
The general goal of the present study was to investigate (a) the effect of a Mediterranean cooling related to the increasing NAO index for the last decades and, (b) the effect of an increased thermal contrast between the Mediterranean Sea and its surrounding lands in global warming conditions. But the conclusion of our study may also apply to anomalies induced by the complex circulation of the Mediterranean Sea itself. Furthermore, due to the narrowness of the Gibraltar Strait, complex hydraulic phenomena can take place and control largely the amount of both in- and outflow, and thus the SST of the whole Mediterranean.

Finally, we note that simulations with a Mediterranean warming $(+2 \mathrm{~K})$ reveal important asymmetric responses compared to the cooling simulations. This is certainly an indication of the strong non-linearity governing the behaviours of the atmospheric transient circulations (Peng et al. 2003).

Acknowledgments This work is supported by the French national programme GICC. Computer resources were allocated by IDRIS, the computer centre of the CNRS. Stimulating discussions with M. Crépon, S. Somot are acknowledged. Comments from Bryan Weare, Claude Frankignoul, the executive editor (E. Schneider) and two anonymous reviewers were helpful.

\section{References}

Alpert P, Ben-Gai T, Baharad A, Benjamini Y, Yekutieli D, Colacino M, Diodato L, Ramis C, Homar V, Romero R, Michaelides S, Manes A (2002) The paradoxical inrease of Mediterranean extreme daily rainfall in spite of decrease in total values. Geophys Res Lett 29(11). DOI 10.1029/2001GL013554

Branstator G (2002) Circumglobal teleconnections, the jet stream waveguide, and the North Atlantic Oscillation. J Clim 15:18931910

Conil S, Li ZX (2005) Linearity of the atmospheric response to North Atlantic SST and Sea Ice anomalies. J Clim 18:19862003

Ferreira D, Frankignoul C (2005) The transient atmospheric response to midlatitude SST anomalies. J Clim 18:1049-1067

Frankignoul C (1985) Sea surface temperature anomalies, planetary waves and air-sea feedback in the middle latitudes. Rev Geophys 23:357-390

Hayes A, Kucera M, Kallel N, Sbaffi L, Rohling EJ (2005) Glacial Mediterranean sea surface temperatures based on planktonic foraminiferal assemblages. Quaternary Sci Rev 24:999-1016

Honda M, Nakamura H, Ukita J, Kousaka I, Takeuchi K (2001) Interannual seesaw between the Aleutian and Icelandic lows. Part I: seasonal dependence and life cycle. J Clim 14:1029-1042

Honda M, Kushnir Y, Nakamura H, Yamane S, Zebiak SE (2005) Formation, mechanisms and predictability of the AleutianIcelandic low seesaw in ensemble AGCM simulations. J Clim 18:1423-1434

Hsu KJ, Cita MB, Ryan WBF (1973) The origin of the Mediterranean evaporites. In: Ryan WBF, Hsu KJ (eds) Initial reports of the deep sea drilling project, vol 13. US Government Printing Office, Washington DC, pp 1203-1231

Hurrell JW (1995) Decadal trends in the North Atlantic Oscillation: regional temperatures and precipitations. Science 269:676-679

IPCC (2001) Climate change 2001: the scientific basis. Projections of future climate change, Chapter 9. Cambridge University Press, London, pp 526-582

Kalnay E, Kanamitsu M, Kistler R, Collins W, Deaven D, Gandin L, Iredell M, Saha S, White G, Woollen J, Zhu Y, Chelliah M,
Ebisuzaki W, Higgins W, Janowiak J, Mo KC, Ropelewski C, Wang J, Leetmaa A, Reynolds R, Jenne R, Joseph D (1996) The NCEP/NCAR 40-rear reanalysis project. Bull Am Meteor Soc 77:437-471

Krijgsman W, Hilgen FJ, Raffi I, Sierro FJ, Wilson DS (1999) Chronology, causes and progression of the Messinian salinity crisis. Nature 400:652-655

Kushnir Y, Robinson WA, Bladé I, Hall NMJ, Peng S, Sutton R (2002) Atmospheric GCM response to extratropical SST anomalies: synthesis and evaluation. J Clim 15:2233-2256

Lascaratos A, Roether W, Nittis K, Klein B (1999) Recent changes in deep water formation and spreading in the eastern Mediterranean Sea: a review. Prog Oceanogr 44(1-3):5-36

Li ZX (1999) Ensemble atmospheric GCM simulation of climate interannual variability from 1979 to 1994 . J Clim 12:986-1001

Li ZX, Conil S (2003a) A 1000-year simulation with the IPSL ocean-atmosphere coupled model. Ann Geophys 46:39-46

Li ZX, Conil S (2003b) Transient response of an atmospheric GCM to North Atlantic SST anomalies. J Clim 16:3993-3998

Malanotte-Rizzoli P, Manca BB, d'Alcala MR, Theocharis A, Brenner Budillon SG, Ozsoy E (1999) The Eastern Mediterranean in the 80s and in the 90s: the big transition in the intermediate and deep circulations. Dyn Atmos Oceans 29(2-4):365-395

Mariotti A, Struglia MV, Zeng N, Lau KM (2002) The hydrological cycle in the Mediterranean region and implications for the water budget of the Mediterranean Sea. J Clim 15:1674-1690

Maugeri M, Bagnati Z, Brunetti M, Nanni T (2001) Trends in Italian total cloud amount, 1951-1996. Geophys Res Lett 28(24):4551-4554. DOI 10.1029/2001GL013754

Milan MM, Estrela JJ, Miro J (2005) Rainfall components: variability and spatial distribution in a Mediterranean Area (Valencia Region). J Clim 18:2682-2705

Norrant C, Douguedroit A (2006) Monthly and daily precipitation trends in the Mediterranean (1950-2000). Theor Appl Climatol 83:89-106, DOI 10.1007/s00704-005-0163-y

Peng S, Whitaker JS (1999) Mechanisms determining the atmospheric response to midlatitude SST anomalies. J Clim 12:13931408

Peng S, Robinson WA, Li S (2003) Mechanisms for the NAO responses to the North Atlantic SST tripole. J Clim 16:1987-2004

Rayner NA, Parker DE, Horton EB, Folland CK, Alexander LV, Rowell DP, Kent EC, Kaplan A (2003) Global analyses of sea surface temperature, sea ice, and night marine air temperature since the late nineteenth century. J Geophys Res 108: No. D14, 4407, doi:10.1029/2002JD002670

Rixen $M$ et al (2005) The Western Mediterranean deep water: a proxy for climate change. Geophys Res Lett 32:L12608, doi:10.1029/2005GL022702

Rowell DP (2003) The impact of Mediterranean SSTs on the Sahelian rainfall season. J Clim 16:849-862

Sadourny R, Laval K (1984) January and July performance of the LMD general circulation model. In: Berger A, Nicolis C (eds) New perspectives in climate modelling. Elsevier, Amsterdam, pp 173-198

Struglia MV, Mariotti A, Filograsso A (2004) River discharge into the Mediterranean Sea: climatology and aspects of the observed variability. J Clim 17:4740-4751

Thompson DWJ, Wallace JM (2001) Regional climate impacts of the Northern Hemisphere annular mode. Science 293:85-89

Watanabe M (2004) Asian jet waveguide and a downstream extension of the North Atlantic Oscillation. J Clim 17:4674 4691

$\mathrm{Yu} \mathrm{R}$, Zhou T (2004) Impacts of winter-NAO on March cooling trends over subtropical Eurasia continent in the recent half century. Geophys Res Lett 31:L12204, doi: 10.1029/ 2004GL019814

Yu R, Wang B, Zhou T (2004) Climate effects of the deep continental stratus clouds generated by Tibetan Plateau. J Clim 17:2702-2713

Zhou TJ, Li ZX (2002) Simulation of the East Asian summer monsoon using a variable resolution atmospheric GCM. Clim Dyn 19:167-180 